\title{
Comparison of Russian, Chinese and European seismic design on pseudo-static seismic coefficient in slope analysis
}

\author{
Kang K. ${ }^{1}$, Zerkal O.V. ${ }^{1}$, Liu J. ${ }^{1}$, Huang S. ${ }^{2}$, Tao D. ${ }^{1.3}$ \\ 1. Geological Faculty, Moscow State University, Moscow 119991, Russia \\ 2. Key Laboratory of Ministry of Education for Hydraulic and Water Transport Engineering, \\ Chongqing Jiaotong University, Chongqing 400074, China \\ 3. Engineering Faculty, China University of Geoscienses (Wuhan), Wuhan 430074, China \\ E-mail: kevinkang8@mail.ru
}

\begin{abstract}
Most design codes and specifications recommend a simple pseudo-static approach for the analysis of slope stability under seismic conditions. The codes in different countries appoint different pseudo-static seismic coefficient. The present work list different seismic coefficients in Russian, Chinese and European codes. A sensitivity analysis of a case slope was carried out using GeoStudio, then determined that the stability of the slope is more sensitive to material cohesion and seismic coefficient than material density and friction angle. It's shown that the chosen of the seismic coefficient has a big effect on slope stability.
\end{abstract}

Keywords: codes; seismic coefficient; pseudo-static method; sensitivity analysis; slope stability.

\section{Introduction}

In Russia, China and Europe there are a few territories suffering from earthquakes, such as Greater Sochi, Province Sichuan, and Italy. These regions are susceptible to seismic landslides or slope failure [1-3]. Although dynamic analysis with considering ground-motion is more advanced than the simplified pseudo-static analysis, most design codes and specifications still recommend the pseudo-static method for conventional projects. In Russia, there are some codes relating to the pseudo-static method for slope analysis, like ODM 218.2.006-2010 [4]. In China different industries specifies different codes on seismic design of slope, like DZ/T0219-2006, DL5073-2000, GB50330-2013, JTJ044-89 and GB50111-2006 [5-9]. In Europe Eurocode 8 is wildly used for slope analysis under seismic condition [10]. In pseudo-static method seismic coefficient appears to be the most important parameter for slope stability analysis. It should be mentioned that the seismic coefficient specified in many codes in China came from the previous codes in USSR [11]. Therefore those values in Chinese codes are same as Russian codes. However, a specification released by China Geological Survey gives a different value from others [5]. In present work, Russian code "ODM 218.2.006-2010" [4], Chinese code "DZ/T0219-2006" [5] and European code "Eurocode 8" [10] are compared on pseudo-static seismic coefficient.

\section{Simplified pseudo-static analysis}

A pseudo-static analysis represents the effects of earthquake shaking by accelerations that create inertial forces. These forces act in the horizontal and vertical directions at the centroid of each slice. In present work, only the horizontal force is considered, as shown in Figure 1. The seismic force is defined as:

$$
F_{h}=k_{h} W
$$

where: $k_{h}$ - horizontal seismic coefficient; $W$ - the material weight.

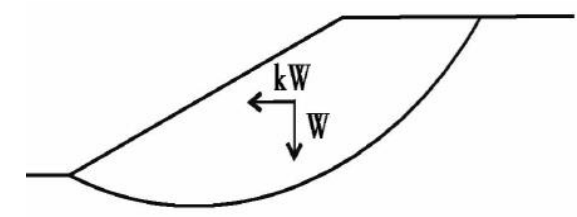

Figure 1. Schematic map of slope analysis with seismic force 


\section{Pseudo-static seismic coefficients in Russian, Chinese and European codes}

Russian code "ODM 218.2.006-2010" specifies seismic coefficients referring to different earthquake intensity as table 1 shows. While, Chinese code "DZ/T0219-2006" and European code "Eurocode 8" indicates values of seismic coefficient which are more than counter-value of Russian code (see table 2-3). It's shown that seismic coefficient in Chinese code can be twice than Russian code; seismic coefficient in European code -4 times than Russian code.

\begin{tabular}{llll} 
Table 1. Seismic coefficient in Russian code "ODM 218.2.006-2010" \\
\hline Earthquake intensity & 7 & 8 & 9 \\
\hline Design ground acceleration & $0.1 \mathrm{~g}$ & $0.2 \mathrm{~g}$ & $0.4 \mathrm{~g}$ \\
\hline Seismic coefficient & 0.025 & 0.05 & 0.1 \\
\hline
\end{tabular}

Table 2. Seismic coefficient in Chinese code "DZ/T0219-2006"

\begin{tabular}{llll}
\hline Earthquake intensity & 7 & 8 & 9 \\
\hline Design ground acceleration & $0.1 \mathrm{~g}$ & $0.2 \mathrm{~g}$ & $0.4 \mathrm{~g}$ \\
\hline Seismic coefficient & 0.1 & 0.2 & 0.4 \\
\hline
\end{tabular}

Table 3. Seismic coefficient in European code "Eurocode 8" on type A ground

\begin{tabular}{llll}
\hline Earthquake intensity & 7 & 8 & 9 \\
\hline $\begin{array}{l}\text { Design ground acceleration } \\
\text { (when according to MSK-64) }\end{array}$ & $0.1 \mathrm{~g}$ & $0.2 \mathrm{~g}$ & $0.4 \mathrm{~g}$ \\
\hline Seismic coefficient & 0.05 & 0.1 & 0.2 \\
\hline
\end{tabular}

\section{Sensitivity analysis of physical-mechanical and seismic parameters}

The simple landslide models with 8 different slope angles of 10, 20, 30,40, 50, 60,70 and 80 are considered in the GeoStudio software with limit equilibrium method (Fig.2). A sensitivity analysis can help analyze which parameter the stability of the slope is more sensitive to [12]. SLOPE/W of GeoStudio allows to specify a value range of the material parameters and seismic effect, and will compute the safety factor automatically when each value of the parameters is used [13]. Based on the experimental result of a mudstone slope case in Sochi(see table 4), the variability of the material properties is known: the unit weight is $18-20 \mathrm{kN} / \mathrm{m}^{3}$, cohesion is $10-25 \mathrm{kPa}$ and friction angle is $25-30^{\circ}$. Regarding seismic coefficient, earthquake intensity is set to be 8 , and the range of values is based on the boundary of different codes. As for Russia, seismic coefficient equals 0.05 according to Russian code "ODM 218.2.006-2010" (see table 1). In Chinese code "DZ/T0219-2006 Specification of design and construction for landslide stabilization", seismic coefficient equals 0.2 corresponding to intensity 8 (see table 2 ). While, Eurocode 8 applied in many European countries indicates that seismic coefficient equals 0.1 in the condition of the design ground acceleration $200 \mathrm{~cm} / \mathrm{s}^{2}$ on type A ground (see table 3). Based on those codes the variation of seismic coefficient is considered from 0.05 to 0.2 during the sensitivity analysis, as shown in table 4 .

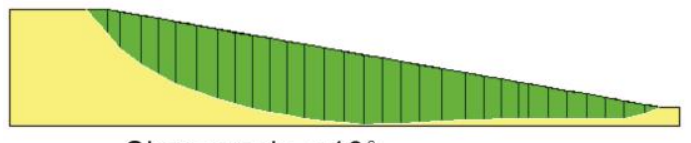

Slope angle $=10^{\circ}$

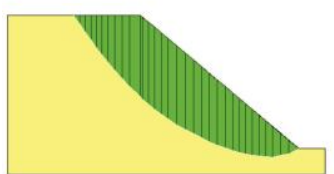

Slope angle $=40^{\circ}$

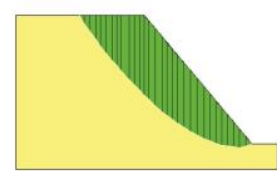

Slope angle $=50^{\circ}$

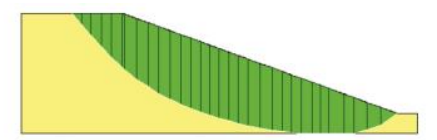
Slope angle $=20^{\circ}$

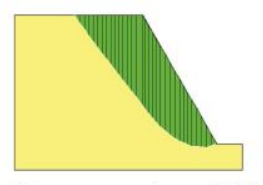

Slope angle $=60^{\circ}$

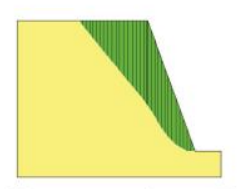

Slope angle $=70^{\circ}$

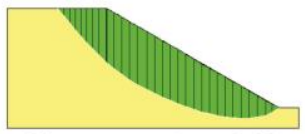

Slope angle $=30^{\circ}$

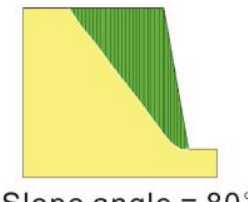

Fig. 2. Analysis models for slope stability from eight different slope angles $\left(10^{\circ}, 20^{\circ}, 30^{\circ}, 40^{\circ}, 50^{\circ}, 60^{\circ}, 70^{\circ}\right.$ and $\left.80^{\circ}\right)$

Table 4. The basic mudstone physical and mechanical parameters of studied slopes and seismic coefficients

\begin{tabular}{cllll}
\hline & $\begin{array}{l}\text { Unit weight } \\
\left(\mathrm{kN} / \mathrm{m}^{3}\right)\end{array}$ & $\begin{array}{l}\text { Cohesion } \\
(\mathrm{kPa})\end{array}$ & $\begin{array}{l}\text { Friction angle } \\
\left({ }^{\circ}\right)\end{array}$ & $\begin{array}{l}\text { Horizontal seismic coefficient } \\
\text { according to different codes }\end{array}$ \\
\hline Range of values & $18-20$ & $10-25$ & $25-30$ & $0.05-0.2$ \\
\hline Average value & 19 & 17.5 & 27.5 & 0.125 \\
\hline
\end{tabular}


The sensitivity analysis was then conducted in slope models with various slope angles. For presentation purposes, all the strengths are normalized to a value ranging between 0.0 and 1.0. Zero means the lowest value and 1.0 means the highest value. For the example here, zero means a cohesion of $10 \mathrm{kPa}$ and a seismic coefficient of 0.05 . A value of 1.0 means a cohesion of $25 \mathrm{kPa}$ and a seismic coefficient of 0.2 .

Sensitivity graphs (Fig. 3-10) show the computed factor of safety (FOS) at different values of the parameters. The crossing point represents the safety factor when the average value of all the parameters is used (see table 1). The results of 8 sensitivity graphs indicate that the safety factor is most sensitive to the cohesion and seismic coefficient, and is least sensitive to the material unit weight and friction angle.

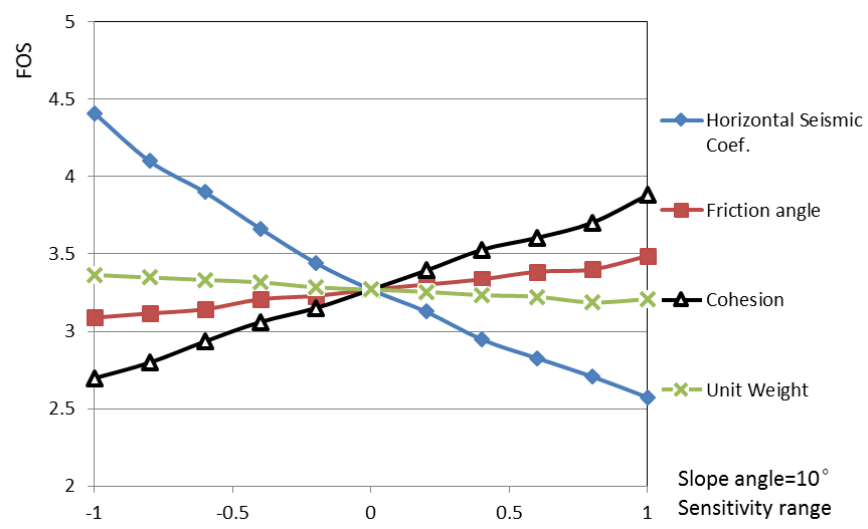

Fig. 3. Sensitivity graph for slope stability with slope angle $=10^{\circ}:$ the safety factor of the slope is most sensitive to the seismic coefficient.

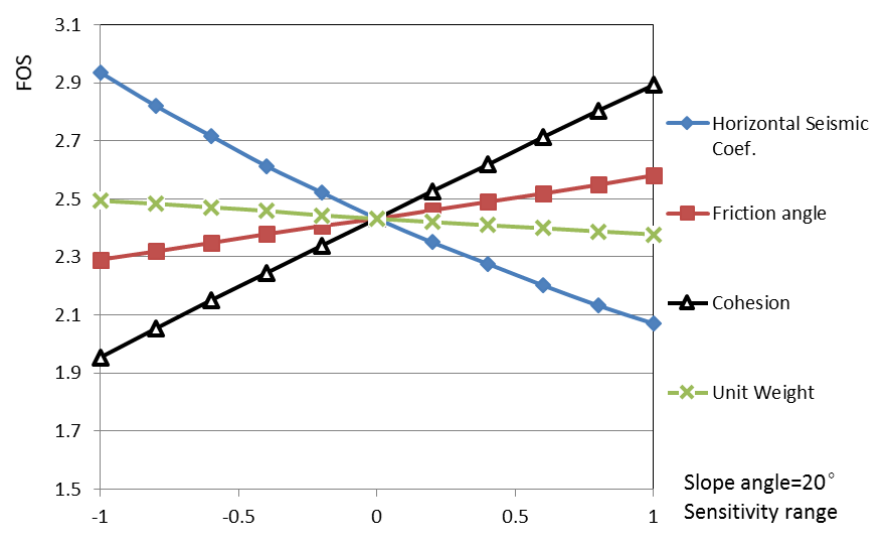

Fig. 4. Sensitivity graph for slope stability with slope angle $=20^{\circ}:$ the safety factor of the slope is most sensitive to the cohesion, while is more sensitive to the seismic coefficient than unit weight and friction angle.

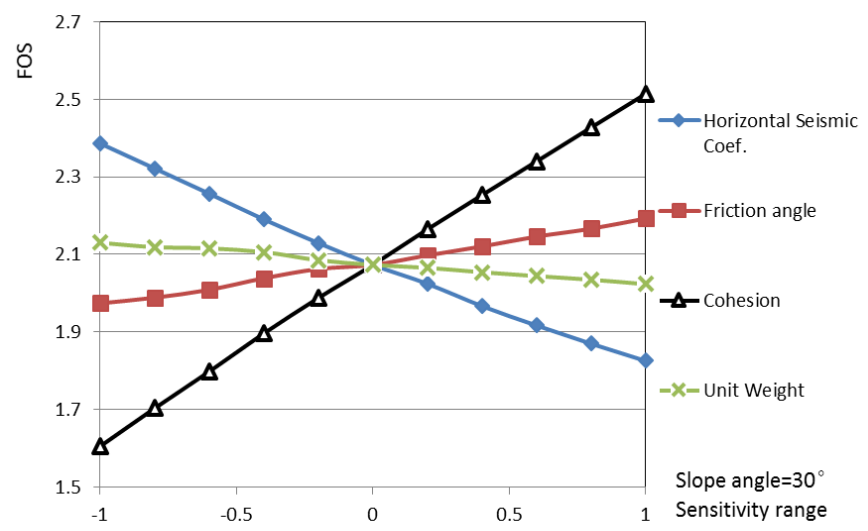

Fig. 5. Sensitivity graph for slope stability with slope angle $=30^{\circ}$ : the safety factor of the slope is most sensitive to the cohesion, while is more sensitive to the seismic coefficient than unit weight and friction angle. 


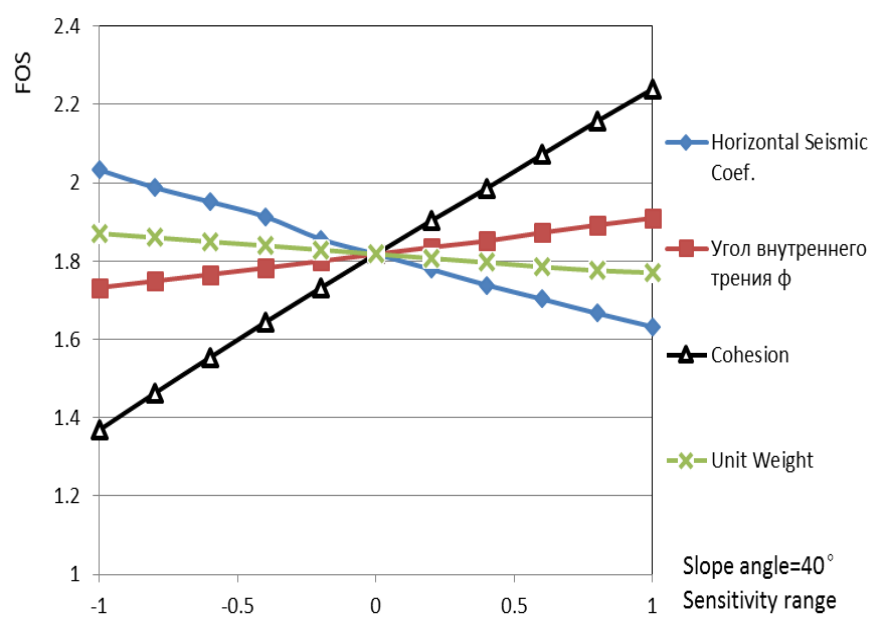

Fig. 6. Sensitivity graph for slope stability with slope angle $=40^{\circ}$ : the safety factor of the slope is most sensitive to the cohesion, while is more sensitive to the seismic coefficient than unit weight and friction angle.

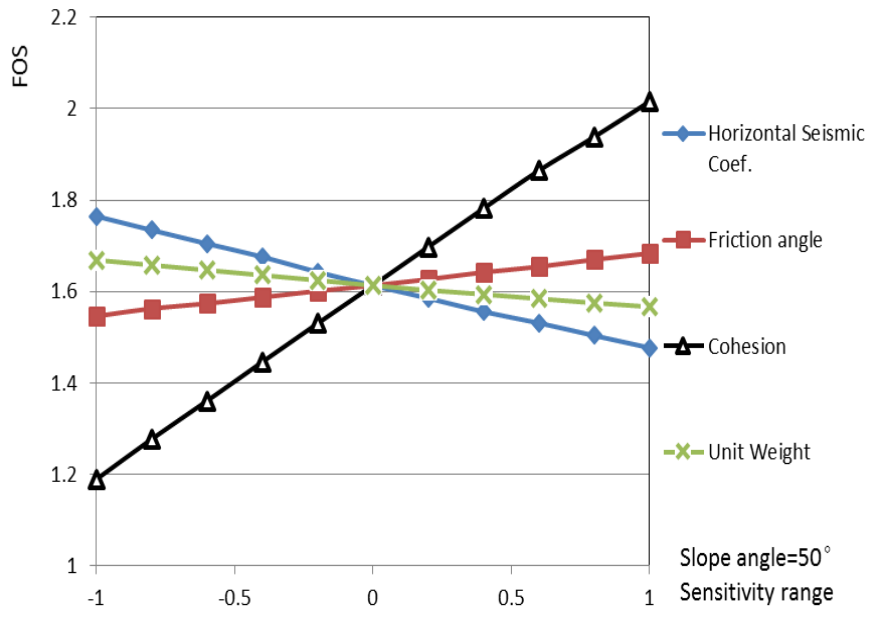

Fig. 7. Sensitivity graph for slope stability with slope angle $=50^{\circ}:$ the safety factor of the slope is most sensitive to the cohesion, while is more sensitive to the seismic coefficient than unit weight and friction angle.

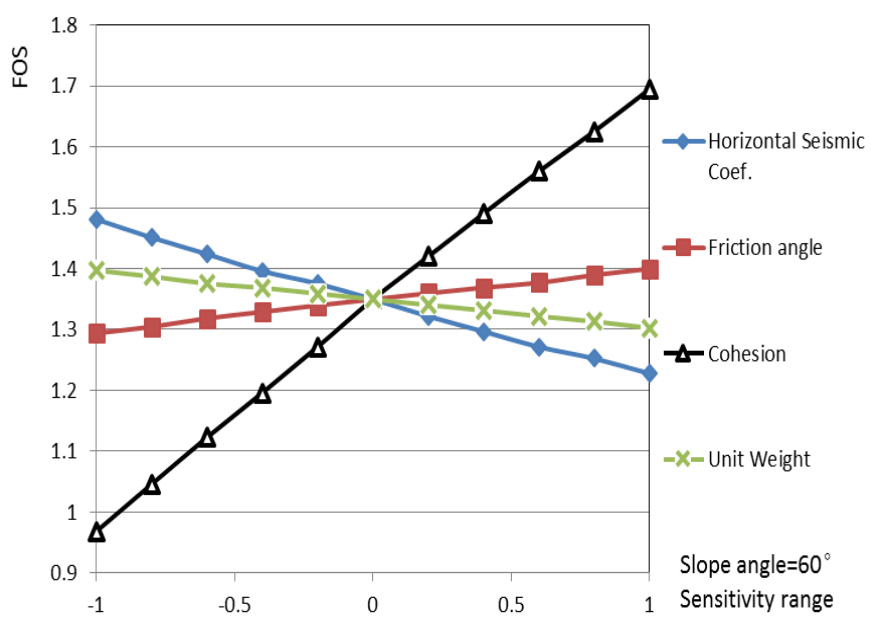

Fig. 8. Sensitivity graph for slope stability with slope angle $=60^{\circ}$ : the safety factor of the slope is most sensitive to the cohesion, while is more sensitive to the seismic coefficient than unit weight and friction angle. 


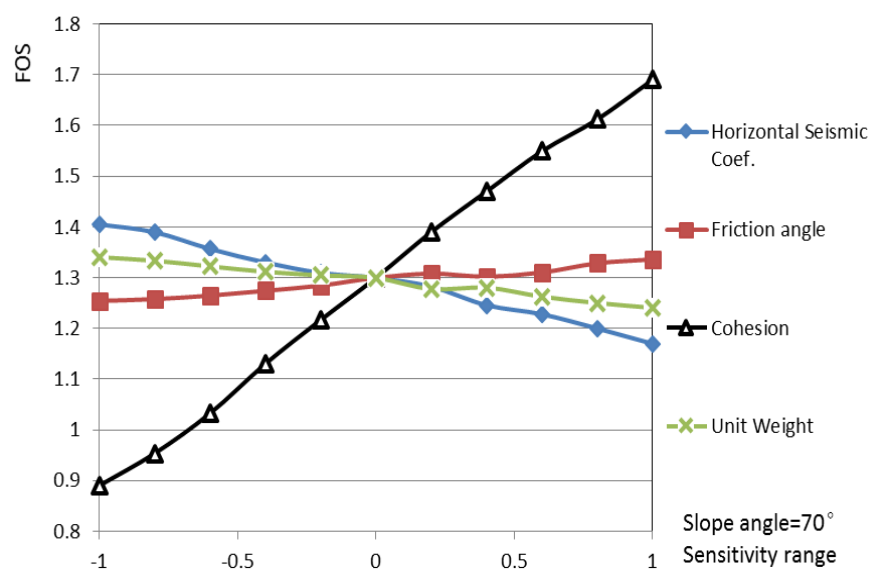

Fig. 9. Sensitivity graph for slope stability with slope angle $=70^{\circ}$ : the safety factor of the slope is most sensitive to the cohesion, while is more sensitive to the seismic coefficient than unit weight and friction angle.

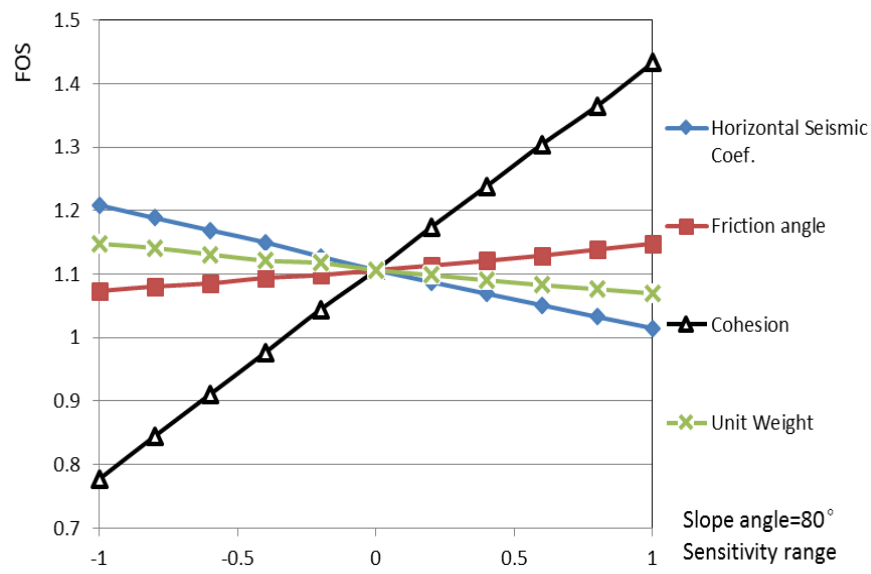

Fig. 10. Sensitivity graph for slope stability with slope angle $=80^{\circ}$ : the safety factor of the slope is most sensitive to the cohesion, while is more sensitive to the seismic coefficient than unit weight and friction angle.

\section{Conclusions}

The different seismic coefficients in Russian, Chinese and European codes are presented. The seismic coefficient turned to be a crucial influence factor on slope stability. A sensitivity analysis shows that the stability of the slope is more sensitive to seismic coefficient and cohesion than material unit weight and friction angle. The chosen of the seismic coefficient has a big effect on slope stability. How to choose a rational seismic coefficient is future work.

\section{References}

[1] Kuzin I P, Levchenko D G, Lobkovsky L I, et al. On the seismic hazard of the Bolshoi Sochi region. Oceanology, 2009, 49(5): 718-728.

[2] Yin Y.P. Catastrophic landslides associated with the M8.0 Wenchuan Ms8.0 Earthquake. Bull Eng Geol Environ, 2010, 70(1):15-32

[3] Nadim, F., Kjekstad, O., Peduzzi, P. , et al. Global landslide and avalanche hotspots. Landslides, 2006, 3(2):159-173.

[4] ODM 218.2.006-2010 Recommendations for the calculation of the landslide stability and the definition of landslide pressures on road engineering structures. The FSUE "Informavtodor", 2011(in Rusian)

[5] China Geological Survey. DZ/T0219-2006 Specification of design and construction for landslide stabilization. Beijing: Standards Press of China, 2006. (in Chinese)

[6] China Institute of Water Resources and Hydropower Research. DL5073-2000 Specifications for seismic design of hydraulic structures. 2000. (in Chinese) 
[7] Chongqing Construction Commission. GB50330-2013 Technical code for building slope engineering. Beijing: China Architecture \& Building Press,2014. (in Chinese)

[8] Highway Planning and Designing Institute, Ministry of Communications. JTJ044-89 Code for seismic design of highway engineering. Beijing: China Communications Press, 1989. (in Chinese)

[9] Ministry of Railways of the People's Republic of China. GB50111-2006 Code for seismic design of railway engineering. Beijing: China Planning Press, 2006. (in Chinese)

[10] Comité Européen de Normalisation (CEN). Eurocode 8, design of structures for earthquake resistance- Part 5:Foundations, retaining structures and geotechnical aspects. European Standard NF EN 1998-5, Brussels, Belgium. 2006.

[11] Yin Yueping, Wang Wenpei. Researches on seismic landslide stability analysis. Journal of Engineering Geology, 2014(4): 586-600.(in Chinese)

[12] El-Ramly, H., Morgenstern, N.R. and Cruden, D.M. Probabilistic slope stability analysis for practice. Canadian Geotechnical Journal, 2002,39(3):665-683.

[13] Krahn, J. Stability Modeling with SLOPE/W, An Engineering Methodology, Third Edition, Prepared and printed in-house by GEO-SLOPE International Ltd, Calgary, Alberta, Canada, 2007. 